\title{
Tear electrolyte assessment of diabetic patients in Southern Nigeria
}

\author{
Juno Okukpon ${ }^{1}$, Oziegbe Okukpon ${ }^{2}$
}

1. University of Benin, Department of Optometry; Applied Environmental Bioscience and Public Health Research Group, Life Sciences, University of Benin.

2. Okukpon, Oziegbe; Irrua specialist teaching hospital, Department of Community Medicine.

\begin{abstract}
Background: Tears are a critical body extracellular fluid coating the surface epithelial cells of the cornea and conjunctiva, and providing the optically smooth surface necessary for refraction of light onto the retina. The biological and chemical properties of tears change in response to systemic disease.

Objectives: This study assessed the concentration of calcium, magnesium and phosphate levels in tears of diabetics.

Methods: A comparative cross-sectional study involving twenty diabetics visiting Department for Health Services, University of Benin and forty non-diabetics within the University between 35 to 65 years participated in the study. Calcium, magnesium and phosphorous were analysed in tears sample collected with $75 \mathrm{~mm}$ glass capillary tubes.

Results: The fasting blood sugar (FBS) and age of diabetic patients was $7.48 \pm 1.88 \mathrm{mmol} / 1$ and $56.75 \pm 5.82$ years and non-diabetics was $4.83 \pm 0.52 \mathrm{mmol} / 1$ and $53.58 \pm 6.16 y e a r s$ respectively. Magnesium showed no differences $(\mathrm{P}<0.05)$ between diabetics $(0.76 \pm 0.45 \mathrm{mmol} / \mathrm{l})$ and non-diabetics $(0.93 \pm 0.59 \mathrm{mmol} / \mathrm{l})$. Calcium was elevated $(\mathrm{P}=0.041)$ and phosphate $(\mathrm{P}=0.044)$ was decreased in diabetics $(3.14 \pm 1.65 \mathrm{mmol} / 1$ and $0.074 \pm 0.058 \mathrm{mmol} / \mathrm{l})$ than non-diabetics $(2.41 \pm 1.05 \mathrm{mmol} / 1$ and $0.11 \pm 0.081 \mathrm{mmol} / \mathrm{l})$. Conclusion: This study concluded that being diabetic can affect the levels of some tear electrolytes in the tear fluid which may lead to an increased risk of diabetic ocular complications.
\end{abstract}

Keywords: Tears, diabetics, mag nesium, calcium, phosphorus.

DOI: https://dx.doi.org/10.4314/ahs.v19i4.5

Cite as: Okukpon J, Okukpon O. Tear electrolyte assessment of diabetic patients in Southern Nigeria. Afri Health Sci. 2019;19(4):28392845.https:/ / dx.doi.org/10.4314/abs.v19i4.5

\section{Introduction}

Diabetes Mellitus (DM) defined by absolute or relative deficiencies in insulin secretion and/or insulin action associated with chronic hyperglycaemia and disturbances of carbohydrate, lipid and protein metabolism. ${ }^{1,2}$ It is a metabolic disorder characterized by a congenital or acquired inability to transport sugar from the bloodstream into the cells, this can cause complications that can affect the ocular tissues, ${ }^{3}$ although a diabetic patient with well controlled blood sugar level can delay the onset or reduce the rate of progression of these complications.

\section{Corresponding author: \\ Juno Okukpon, University of Benin, Department of \\ Optometry; Applied Environmental \\ Bioscience and Public Health \\ Research Group, Life Sciences, \\ University of Benin. \\ Email: juno.okukpon@uniben.edu}

Tear film consists of three layers, the lipid component produced by the meibomian glands that are located in the eyelids and responsible for impeding tear loss through, ${ }^{4,5}$ the most significant portion of the tear film by volume, is the aqueous portion produced by the lacrimal gland, contains electrolytes and hundreds of proteins and peptides, ${ }^{5}$ the mucin layer is comprised of mucins that are constituted largely of sugars. ${ }^{6,7}$ Tears exert various homeostatic effects on the ocular surface. ${ }^{8-10}$ Maintenance of an appropriate osmotic gradient of tear electrolytes between the tear film and the ocular surface epithelia is therefore vital, as any imbalance of these electrolytes may be the beginning of many pathologies. ${ }^{11}$

Electrolytes are essential for human health and have diverse metabolic characteristics and functions. ${ }^{12,13}$ They are electrically charged molecules with various functions, including fluid balance, tissue function, ${ }^{13}$ maintaining homeostasis in the body, protecting cellular function, acid-base balance and so on. ${ }^{12,14}$ The ocular surface epi-

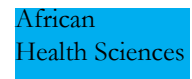

(C) 2019 Okukpon et al. Licensee African Health Sciences. This is an Open Access article distributed under the terms of the Creative commons Attribution License (https://creativecommons.org/licenses/BY/4.0), which permits unrestricted use, distribution, and reproduction in any medium, provided the original work is properly cited. 
thelium does not have blood supply thus it derives electrolytes and oxygen from the tear film, making the tear film a vital fluid. ${ }^{15}$

Calcium, phosphorus and magnesium are multivalent cations and relevant in a number of biological functions. ${ }^{16}$ Magnesium is responsible for numerous biochemical reactions in the body. ${ }^{17}$ It also helps promote good blood circulation and any deficiency may play a role in the development of endothelial dysfunction and altered insulin function. ${ }^{12}$ Calcium works closely with phosphorous and magnesium and is critical for a variety of functions especially neuromuscular excitability and irritability. ${ }^{16}$ Phosphorous is an essential component of cellular membrane phospholipids and intracellular compounds like nucleic acids and nucleoprotein, also most intracellular phosphorous exist as organic phosphate. ${ }^{16}$ Phosphorous is also important in acid-base balance, cell wall structure, oxygen transportation and energy storage. ${ }^{18}$ The normal magnesium, calcium and phosphorous (expressed as phosphates) concentration found in tears are $0.3-1.1 \mathrm{mmol} / \mathrm{L}$, $0.3-2.4 \mathrm{mmol} / \mathrm{L}$ and $0.07 \mathrm{mmol} / \mathrm{L}$ respectively. ${ }^{15,19,20}$

Previous studies ${ }^{13,18,21}$ have shown alterations in serum levels of these electrolytes with glucose levels in plasma but limited studies ${ }^{20}$ are available on tears electrolyte levels. Gilbard and Pardo, ${ }^{15}$ reported that imbalance of tear fluid electrolytes can be associated with electrolyte imbalance toxicity. Gilbard and Pardo, ${ }^{15}$ further noted that this toxicity can result in ocular changes which includes increased corneal epithelial cell desquamation and loss of conjunctival goblet-cell density. Futhermore, preservation of an accurate osmotic gradient of tear film electrolytes between the tears and the ophthalmic surface epithelia is necessary in regulating cell function/homeostasis.

This study assessed the concentration of three of the macro-minerals/electrolytes; Magnesium, Calcium and Phosphorous in tears sample from patients with diabetics and compared these samples with healthy participants. This study will help understand the imbalance of these electrolyte in DM patients and their relationship with ocular complications like diabetic retinopathy, diabetic duration, age, diabetic medications, and FBS.

\section{Materials and methods}

The comparative cross-sectional study design was utilized for this study. Type II diabetes mellitus patients (cases) were drawn from the Endocrinology unit and non-diabetic subjects (controls) drawn from staff/students.
A total of 60 subjects (20 diabetics and 40 non-diabetic between 35-65 years) were used in this study. Ethical approval was obtained from the ethical committee of the Department Of Optometry, University of Benin (EC/ UBEN/LSCOPT/17/007). A letter of approval for the study was also obtained from the Department for Health Services. Written signed consent was obtained from every subject after careful explanation of the procedure. The research was done according to the tenets of Helsinki declaration involving human subjects. The study targeted medically diagnosed Type II DM patients within the age group on diabetic treatment schedule who visited the study site at regular intervals.

Data forms were filled by each patient and information that they could not remember was obtained from their case notes. Data such as patient's age diabetic duration and anti-diabetic medications was gotten from the data form. All Subjects were screened for their FBS level and any other ocular condition.

\section{Collection of tear sample and storage}

Cotton wool soaked with methylated spirit was used to clean the skin around the eye while the eye was closed and allowed to dry before collecting the tear samples. Tear samples (sample volume about $6 \mu \mathrm{l}$ ) were collected using $75 \mathrm{~mm}$ micro-point glass capillary tubes, then stored at $4^{\circ} \mathrm{C}$ until further analysis. To exclude individual differences, tear collection was done by one examiner only.

Magnesium and calcium were analysed using Bulk Scientific Atomic Absorption Spectrophotometer 210 VGP. Tears sample were introduced into a volumetric flask. Reagent blank was prepared same way as the sample but without the sample to ensure proper calibration. Magnesium or calcium phase was keyed in and the instrument was allowed to reset. Then the probe was inserted into the reagent blank before it was inserted into each sample to get the readings. After each reading the probe was inserted into the reagent blank to recalibrate the instrument. Phosphorous was analysed using 6715 UV Visible Spectrophotometer. A prepared reagent blank was used to calibrate the instrument. Tear sample was turned into laboratory tube and Ammonium Molybdate solution which served as colour developer was added for each sample. The whole solution was then placed in the instrument and the reading was obtained. After each result was obtained, the reagent blank was placed back in the instrument to recalibrate it. 
Data was coded and entered into SPSS version 22.0. Chi square was used to check for relationship between variables, Pearson correlation coefficient was used to determine correlation while One-way analysis of variance (one-way ANOVA) was used to compare mean differences between variables. Values were expressed as mean \pm $\mathrm{SD}$ and $\mathrm{P}<0.05$ were considered statistically significant.

\section{Results}

Over a third of the participants $(35.0 \%)$ in the diabetic group had a diabetic duration of more than eight years. Cataracts were the most common complication among patients who had developed ocular complications. Alpha glucosidase inhibitors $(25.0 \%)$ and insulin sensitizers $(25.0 \%)$ were the most predominant class of drug used by the diabetics (Table I).

Table I: Frequency distribution of variables for Diabetic subjects

\begin{tabular}{lcc}
\hline Variables & Frequency $(\mathrm{n}=20)$ & Percent $(100 \%)$ \\
\hline Diabetic Duration & 2 & \\
0-2 years & 7 & $10.0 \%$ \\
2-4 years & 1 & $35.0 \%$ \\
4-6 years & 3 & $5.0 \%$ \\
6-8 years & 7 & $15.0 \%$ \\
$>8$ years & & $35.0 \%$ \\
Ocular complications & 11 & \\
None & 5 & $55.0 \%$ \\
Cataract & 1 & $25.0 \%$ \\
Glaucoma & 2 & $5.0 \%$ \\
Diabetic retinopathy & 1 & $10.0 \%$ \\
Macular scar & & $5.0 \%$ \\
Diabetic Medications & 2 & \\
None & 1 & $10.0 \%$ \\
Insulin & 4 & $5.0 \%$ \\
Insulin secretagogues & $5 \% .0 \%$ \\
Alpha glucosidase inhibitors & 5 & $25.0 \%$ \\
Insulin sensitizers & 5 & $25.0 \%$ \\
More than 1 & 3 & $15.0 \%$ \\
\hline
\end{tabular}

The mean age for the diabetics and non-diabetics were $56.75 \pm 5.82$ years and $53.58 \pm 6.16$ years respectively $(\mathrm{P}=0.06)$ (Table II). The mean diabetic duration for the diabetic group was $3.30 \pm 1.53$ years (Table II). FBS was higher $(\mathrm{P}=0.0001)$ in the diabetic group than the control, there was a statistically significant difference in calcium $(\mathrm{P}=0.041)$ and phosphorus $(\mathrm{P}=0.044)$ level between the study and the control group, however this was not the case for magnesium levels $(\mathrm{P}=0.220)$ between the study and control groups (Table II, Figure 1). 
Table II: Descriptive Statistics showing difference in mean between Diabetics and Non Diabetics

\begin{tabular}{llccc}
\hline Variables & & $\begin{array}{c}\text { Diabetics } \\
\mathrm{N}=20\end{array}$ & $\begin{array}{c}\text { Non-Diabetics } \\
\mathrm{N}=40\end{array}$ & $P$-value \\
\hline Age (Years) & Male & $58.58 \pm 3.80$ & $58.14 \pm 6.49$ & 0.06 \\
& Female & $54.00 \pm 7.41$ & $52.61 \pm 5.72$ & \\
Diabetic duration & Male & $\mathbf{3 . 5 8} \pm \mathbf{0 . 2 5}$ & - & - \\
(Years) & Female & $\mathbf{2 . 8 6} \pm \mathbf{0 . 3 1}$ & - & \\
FBS (mmol/L) & Male & $7.49 \pm 0.34$ & $5.17 \pm 0.44$ & $0.0001^{*}$ \\
& Female & $7.48 \pm 0.41$ & $4.76 \pm 0.20$ & \\
Magnesium & Male & $0.59 \pm 0.32$ & $0.69 \pm 0.33$ & 0.220 \\
(mmol/L) & Female & $0.97 \pm 0.54$ & $0.99 \pm 0.63$ & \\
Calcium (mmol/L) & Male & $3.23 \pm 1.86$ & $2.51 \pm 1.46$ & $0.041^{*}$ \\
& Female & $3.00 \pm 1.39$ & $2.38 \pm 0.97$ & \\
Phosphate (mmol/L) & Male & $0.049 \pm 0.032$ & $0.12 \pm 0.058$ & $0.044^{*}$ \\
& Female & $0.11 \pm 0.073$ & $0.11 \pm 0.082$ & \\
\end{tabular}

Mean \pm SD, $\mathrm{P}>0.005, \mathrm{FBS}=$ Fasting blood sugar, ${ }^{*}$ statistically significant

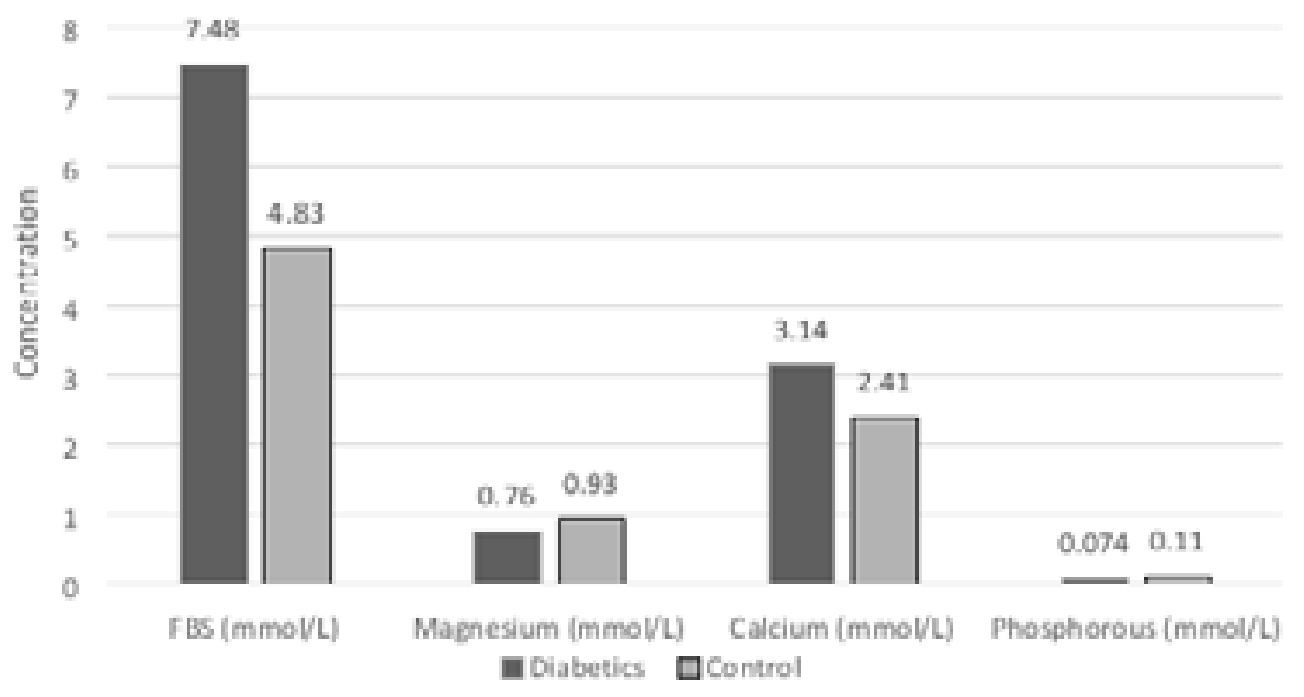

Figure 1: Differences in mean FBS, magnesium, calcium and phosphorous in the diabetic and control group

There was no relationship between the age of respondents and FBS. This was however not the case with other variables. Magnesium showed a relationship with only the ocular conditions of diabetic subjects. We also found a relationship between calcium and FBS and also with patients' diabetic medications. Whereas, phosphorous showed relationships with all the variables except FBS and diabetic duration (Table III). 
Table III: Relationship between FBS, Magnesium, Calcium and Phosphorous with othervariables

\begin{tabular}{lcccccc}
\hline Variables & FBS & Age & $\begin{array}{c}\text { Diabetic } \\
\text { Medications }\end{array}$ & $\begin{array}{c}\text { Ocular } \\
\text { Conditions }\end{array}$ & $\begin{array}{c}\text { Chronic } \\
\text { Conditions }\end{array}$ & $\begin{array}{c}\text { Diabetic } \\
\text { Duration }\end{array}$ \\
\hline FBS(mmol/L) & - & 0.088 & $0.0001^{*}$ & $0.0001^{*}$ & $0.0001^{*}$ & $0.0001^{*}$ \\
$\mathrm{Mg}^{+}(\mathrm{mmol} / \mathrm{L})$ & 0.117 & 0.155 & 0.492 & $0.014^{*}$ & 0.388 & 0.509 \\
$\mathrm{Ca}^{2+}(\mathrm{mmol} / \mathrm{L})$ & $0.0001^{*}$ & 0.593 & $0.043^{*}$ & 0.306 & 0.254 & 0.119 \\
$\mathrm{P}(\mathrm{mmol} / \mathrm{L})$ & 0.059 & $0.042^{*}$ & $0.019^{*}$ & $0.0001^{*}$ & $0.003^{*}$ & 0.337 \\
\hline
\end{tabular}

Magnesium $\left(\mathrm{Mg}^{+}\right)$, Calcium $\left(\mathrm{Ca}^{2+}\right)$, Phosphorus (P), Fasting blood sugar (FBS), $P<0.05, *$ statistically significant

There was no correlation $(\mathrm{P}>0.05)$ between magnesium and the other variables, similarly FBS and age of the diabetics also showed no correlations $(\mathrm{P}>0.05)$ with calcium but a positive correlations with diabetic duration $(\mathrm{r}=$ $0.345, \mathrm{P}=0.007)$. However, phosphorous showed no correlations $(\mathrm{P}>0.05)$ with age and diabetic duration but a weak negative correlation was found with the FBS ( $\mathrm{r}=$ $-0.257, \mathrm{P}=0.048$ ).

\section{Discussion}

Electrolytes play an essential function in metabolism and cell function, which involves enzyme activities and electrical gradients. ${ }^{21}$ Electrolyte imbalances may occur in subjects with DM that is due to a number of factors including hyperglycaemia, deficiency in insulin and hyperketonemia in these patients. ${ }^{13,21} \mathrm{~A}$ finding of higher than normal blood glucose level was found in diabetics, known as hyperglycaemia commonly found in patients with uncontrolled diabetic mellitus occurring as a result of elevated blood sugar levels has been reported in a number of studies. 22,23

Magnesium levels in tears of the diabetic patients compared to the non-diabetics showed no significant variations although levels in the diabetics were lower, as reported by some previous studies. ${ }^{13,21-25}$ However the differences noted was significant although these studies were carried out in serum samples and not tears. Although findings in the current study were not significant, it has been reported that even low magnesium levels that are still within normal reference range are associated with all-cause mortality in patients with Type $2 \mathrm{DM} .^{26}$ This could be as a result of the increased incidence of hypomagnesaemia among patients with type $2 \mathrm{DM}$ and also because of altered insulin metabolism, poor glycaemic control and osmotic diuresis. ${ }^{27}$ Magnesium has been shown to increase blood flow, have neuro-protective effect, important in maintaining normal ionic homeostasis of the lens, decreases oxidative stress and apoptosis in retinal tissue and to have retinal ganglion cell sparing effect. ${ }^{13,17,28}$ Therefore, alterations in magnesium levels may be associated with increased likelihood or progression of retinopathy, cataract and glaucoma in the diabetic population. ${ }^{13,28}$

The result of this study showed differences in tear calcium levels between both groups, with the diabetics showing higher levels, similar to reports of other researchers with serum as sample. ${ }^{21,29}$ Calcium is mainly reabsorbed in the proximal tubule, this reabsorption is coupled with sodium absorption, and it appears to compete with magnesium for transport in the loop of Henle. ${ }^{21}$ The Resnick ionic hypothesis suggested that metabolic disorders, such as diabetes, share a common, altered intracellular condition, characterized by decreased magnesium level leading to concurrent elevation of free intracellular calcium lev$\mathrm{el},{ }^{21}$ this is due to magnesium functioning as a physiologic calcium channel blocker. ${ }^{17}$ The regulation of membrane permeability of the cells and also neuromuscular activity has been attributed to calcium, hence the maintenance of calcium homeostasis is valuable to the ocular tissues especially in the clarity of the lens but with cataract, however, lens membrane permeability increases further. ${ }^{30}$ In addition, elevated calcium levels can result to deposition of calcium on the cornea also known as band keratopathy. ${ }^{16}$ Low phosphate levels as reported in this study has been seen in patients with diabetic ketoacidosis. ${ }^{16,25}$ Confirmation of electrolyte imbalance in phosphate metabolism from the patients with DM, including those with early onset of the condition has signified that this imbalance can result to decrease in cellular high energy phosphates which 
includes the cells of the ocular tissue. ${ }^{25}$ This reduction in high energy phosphates can lead to dysfunction in the cell tissues in turn causing life threatening complications. Diabetes can also be associated with various degrees of intracellular phosphate depletion further increasing the risk of complication, when the phosphate levels is not sufficient for adenosine triphosphate synthesis, inappropriate maintenance of cellular homeostasis occurs which can therefore lead to cell lyses. Ocular tissues similar to other tissues in the body, are susceptible to changes in response to these imbalance leading to pathologies. ${ }^{28}$

\section{Conclusion}

The predominant ocular condition present in patients with DM in this study was cataract. This study found a relationship between magnesium and patients' ocular conditions, Calcium on the other hand showed a relationship with FBS and lastly, phosphate a relationship with ocular/chronic conditions and a weak relationship with age of the diabetic patients. This study also concluded that diabetic medications used by these patients affected their fasting blood sugar as expected since this is part of the management regimen but it however also affected the calcium and phosphate levels in diabetics. Calcium, phosphate and magnesium have important intracellular and extracellular functions with their metabolism often linked through common hormonal signals. The combination of intracellular and extracellular electrolyte disturbances may be implicated in the pathogenesis of neuropathy, nephropathy and vascular complications in diabetic patients. The ocular system needs a balance of electrolytes to maintain normal health, these alterations in electrolyte levels may underlie many of the pathophysiologic and clinical characteristics of diabetes including ocular complications seen in DM. This study found that there are electrolyte imbalances in magnesium, calcium and phosphorous in tears of diabetics which can affect the proper functioning of the ocular system that may encourage ocular complications to occur in these patients if plasma blood glucose is not kept at normal range.

\section{Conflict of interest}

None declared.

\section{References}

1. Abou-Seif AM, Youssef A. Evaluation of some biochemical changes in diabetic patients. Clinica Chimica Acta. 2004; 346:161-70 PubMed
2. Liamis G, Liberopoulous E, Barkas F, Elisaf M. Diabetes Mellitus and Electrolytes Disorders. World Journal of Clinical Cases. 2014; 2(10): 488-96.

3. Khurana AK. In: Comprehensive Ophthalmology. (Fourth edition). New age international publishers. 2007

4. Lemp MA. Advances in understanding and managing dry eye disease. American Journal of Ophthalmology. 2008; 146: 350-6.

5. Morgan P. Tear Film Proteins: Examining Production, Role and Interaction with Contact Lenses. Contact Lens Spectrum/special edition. 2010; 34-9.

6. Efron N. Contact Lens Practice. (2nd edition). Oxford, UK: Butterworth Heinemann. 2010.

7. Maskin SL. Reversing Dry Eye Syndrome: Practical Ways to Improve Your Comfort, Vision, and Appearance. New Haven, CT: Yale University Press; 2007

8. Tiffany JM. Tears in health and disease. Eye (London). 2003; 17:923-6.

9. Peters E, Colby K. The Tear Film. Physiology of the Eye and Visual System. In: Tasman, William; Jaeger, Edward A (ed.). Duane's Foundations of Clinical Ophthalmology. Philadelphia, PA: Lippincott Williams \& Wilkins. 2009

10. Kawai S, Nakajima T, Hokari S, Komoda T, Kawai K. Apolipoprotein A-I concentration in tears in diabetic retinopathy. Annals of Clinical Biochemistry. 2002; 39: 56- 61 11. Woodward AM, Senchyna M, Argüeso P. Differential contribution of hypertonic electrolytes to corneal epithelial dysfunction. Experimental Eye Research. 2012; 100: 98-100 PubMed .

12. Ahmed S, Nur, Shahjahan M. Factor's influencing electrolyte imbalance in diabetic patients. 2013 DOI.10.13140/RG.2.1.4882.4164.

13. Deepti GN, Sumina C, Lakshmi K. A comparative study of electrolyte imbalances in controlled and uncontrolled diabetes mellitus. International Journal of Clinical and Biochemistry Research. 2017; 4(1):22-4

14. Goldberg A, Hammerman H, Petcherski S, Zdorovyak A, Yalonetsky S, Kapeliovich M, et al. Prognostic importance of hyponatremia in acute ST-elevation myocardial infarction. American Journal of Medicine. 2004; 117(4):242-8.

15. Gilbard JP, Pardo D. Lubricant eye drops: The electrolyte factor. Optometry Today. 2005

16. Amit KG, Shashank RJ. Disorders of Calcium, Phosphorus and Magnesium Metabolism. JAPI. 2008 Aug; 56:613-21

17. Korkmaz S, Ekici F, Tufan HA, Aydın B. Magnesium: 
Effect on ocular health as a calcium channel antagonist. Journal of Clinical and Experimental Investigations. 2013; 4 (2): 244-51

18. Baker SB, Worthley LI. The essentials of calcium, magnesium and phosphate metabolism: part I. Physiology. Critical Care and Resuscitation. 2002 Dec; 4(4):301-6. 19. Stahl U, Willcox M, Stapleton F. Osmolality and tear film dynamics. Clinical and Experimental Optometry. 2012; 95(1): 3-11

20. Wei XE, Markoulli M, Millar TJ, Willcox MDP, Zhao Z. Divalent Cations in Tears, and Their Influence on Tear Film Stability in Humans and Rabbits. Investigative Ophthalmology and Vision Science. 2012; 53: 7

21. Wang S, Hou X, Liu Y, Lu H, Wei L, Bao Y, et al. Serum electrolyte levels in relation to macrovascular complications in Chinese patients with diabetes mellitus. Cardiovascular Diabetes. 2013: 12:146

22. Lasisi TJ, Fasamande AA. Salivary flow and composition in diabetic and non-diabetic subject. Nigerian Journal of Physiological Science. 2012; 27: 79-82.

23. Hosen B, Buiyan AR, Hasan S, Hassan M, Uddin M. Estimation of serum electrolytes in non-insulin dependent (type 2) diabetic patients in Bangladesh. Science Research Journal. 2014; 2(12): 29- 32.

24. Syed MS, Roomana R, Tabassum M. Electrolytes and sodium transport mechanism in diabetes mellitus. Pakistan Journal of Pharmaceutical Sciences. 2005 April; 18 (2):610

25. Ogunleye AZ, Asaolu MF. Evaluation of Macro Minerals in Patients with Type II Diabetes Mellitus in Southern Nigeria. IJBCRR 2016; 9(2): 1 - 9

26. Neha S, Umesh KP, Avdheshkumar S, Ketan M, Mali KL, Kaushik GG. Comparative study of role of Macro minerals \& Electrolytes with Atherogenic index of plas$\mathrm{ma}$ in Diabetic men and women. Medical Science. 2014; 13(50): 32-8.

27. Mooren FC, Kruger VK, Golf SW, Wadephill M, Kraus A. Oral magnesium supplementation reduces insulin resistance in diabetic and non-diabetic subject. Diabetes Obesity Metabolism. 2011 Mar; 13 (3): 281-4.

28. Agarwal R, Iezhitsa I, Agarwal P. Pathogenetic role of magnesium deficiency in ophthalmic diseases. Biometals. 2014; 27:5-18 PubMed .

29. Christian SB, Chavda SA, Bardsara, JD. Serum Electrolytes Levels in Type 2 Diabetes Mellitus Patients. IJAR. 2015; 31(4): 997 PubMed -1001

30. Tang D, Borchman D, Yappert MC, Vrensen GFJ, Rasi V. Influence of Age, Diabetes, and Cataract on Calcium, Lipid-Calcium and Protein-Calcium Relationships in Human Lenses. Investigative Ophthalmology and Vision Science. 2003 May; 44(5): 2059-66 